\title{
NOVAS TECNOLOGIAS APLICADAS EM UMA PÓS-GRADUAÇÃO A DISTÂNCIA: O CASO GVnext
}

\author{
Marta de Campos Maia \\ Fundação Getulio Vargas - FGV-EAESP - mmaia@fgvsp.br \\ Fernando de Souza Meirelles \\ Fundação Getulio Vargas - FGV-EAESP - meirelles@fgvsp.br
}

\begin{abstract}
Resumo
A utilização das novas tecnologias de informação e de comunicação (TIC) tem contribuído para a transformação do aprendizado. Uma parte significativa desta transformação está relacionada à aplicação de tais tecnologias com os já conhecidos recursos educacionais na educação a distância (EAD), como veículo para alcançar novos públicos e desenvolver novas metodologias de ensino, as quais possam ser utilizadas como mecanismo complementar, substitutivo ou integrante do ensino presencial.

Um dos fatores críticos de sucesso em EAD é o seu foco direcionado para as necessidades dos alunos e a definição de conteúdos que atendam a estas necessidades.

Levando em consideração tais fatores, destacamos que o objetivo deste trabalho é apresentar o modelo educacional, permeados pela tecnologia de informação e comunicação, adotados pelo GVnet no curso a distância para executivos, o GVnext.
\end{abstract}

Palavras- chaves: tecnologias educacionais; educação a distância e pós-graduação

\section{Introdução}

O capital da sociedade do conhecimento não será mais a matéria-prima ou bens produzidos e acumulados, mas sim o conhecimento, de acordo com Drucker (1999) e Toffler (1990). Assim, do mesmo modo que demandamos por mais bens materiais, nesta nova sociedade deveremos demandar por mais conhecimento. A sociedade da informação sintetiza o surgimento de um paradigma técnico/econômico, no qual a informação é o insumo central.

A ampliação do conhecimento acumulado pela sociedade tem sido expressiva nos últimos tempos e, através da Internet, o homem atual possui um acesso muito maior às informações, de maneira extremamente rápida em comparação a épocas passadas.

Mas, conforme citado por Valente (2002), o fato de termos abundância de informação, não significa que as pessoas têm mais conhecimento. O conhecimento é produto do processamento da informação. Mas como será possível incentivar esse processamento como ele acontece?

Para atingimos melhores níveis de educação em nosso país é necessário criar meios para que as pessoas possam ter a chance de construir conhecimento e, portanto, é necessário aumentar a oferta da educação.

Através da aplicação da tecnologia na educação pode mudar esta perspectiva, pois o desenvolvimento de novas tecnologias, que tem provocado uma revolução silenciosa na sociedade, também tem transformando os meios de fazer negócio, o modo de trabalhar das pessoas, também tem permitido outras possibilidades de ensino/aprendizagem. Propiciaram o desenvolvimento de novas alternativas na modalidade de Educação a Distância (EAD), que combinam os já conhecidos recursos educacionais, com as ferramentas das modernas tecnologias de informação e comunicação (TICs).

A Internet, nos últimos anos, tem propiciado diversas mudanças na área educacional, quer seja pela tecnologia utilizada, como também na forma de apresentação do conteúdo didático de um curso. A mudança pode ser percebida desde o escopo, o conteúdo e o oferecimento 
do ensino a distância. É neste contexto que a Educação a Distância vem surgindo como uma das mais importantes ferramentas de difusão de educação e conhecimento.

Um dos principais desafios para as IES que estão se lançando na EAD é buscar uma linguagem pedagógica apropriada à aprendizagem mediada pelas diversas mídias disponíveis. $\mathrm{O}$ controle e o acompanhamento permanente pela coordenação geral do curso do trabalho de professores, dos tutores, dos estagiários de atendimento e da secretaria, são igualmente cruciais, pois a interação com o aluno pode se dar de inúmeras formas e todas elas são essenciais ao sucesso da aprendizagem. A estruturação de uma equipe especializada, composta de pessoas que entendam de tecnologia e de pedagogia e, que trabalhem de forma coesa, podem garantir um melhor resultado na aprendizagem do aluno.

\section{Referencial Teórico}

Estruturação de um Curso a Distância

O planejamento da estrutura de um curso a distância é de fundamental importância para as IES que pretendem se lançar na EAD: além de lidar com a complexidade do cenário nacional, ainda precisam se preocupar com aspectos estruturais que garantam a certificação dos cursos, conforme requisitos do MEC.

Existem questões sobre a estruturação que são comuns a todos os modelos de $\mathrm{EAD}$, e levam à análise da estrutura que é necessária para as alternativas de Educação a Distância utilizadas pelas IES, considerando as especificidades do conteúdo e dos requerimentos de cada tipo de certificação.

Os vários modelos de educação de distância são construídos ao redor dos componentes centrais do processo instrutivo: apresentação de conteúdo; interação e formas de acesso com a universidade, com os demais alunos, e com os recursos; aplicação prática e avaliação. Cada modelo de EAD utiliza e combina tecnologias de várias maneiras para atender alguns ou todos estes componentes. Os vários modelos de educação de distância não só diferem nos tipos de tecnologias que são usadas, mas também a forma de controle do aprendizado e o local de instrução. Em alguns modelos, os docentes e a instituição têm um controle primário, como é o caso em um ambiente de sala de aula tradicional. Em outros, o controle é "deixado" com o estudante.Sistema de Distribuição e Tecnologias disponíveis para a educação a Distância

Analisando o trabalho desenvolvido por Vygotsky (1998), que destaca a importância da relação e da interação com outras pessoas como origem dos processos de aprendizagem e desenvolvimento humano, e o trabalho de Jensen et. al (1999), que destaca o papel da comunicação no estabelecimento de sentimentos de colaboração e confiança, conclui-se que o uso de ferramentas de comunicação que suportem as interações colaborativas de aprendizagem entre professores e alunos é de fundamental importância para a eficácia do processo educativo num curso a distância.

A comunicação de forma eletrônica pode ser categorizada de diversas formas, mas a distinção mais usual é entre a síncrona e a assíncrona. A comunicação assíncrona não requer participação simultânea, sendo portanto mais flexível: os alunos podem escolher seu próprio ritmo para a aprendizagem e podem obter os conteúdos de acordo com a sua programação pessoal. Esta comunicação pode ser feita através de correio eletrônico, de listas de discussão, apresentação de vídeos, cursos por correspondência e cursos baseados na web. As vantagens da comunicação assíncrona incluem a escolha do estudante quanto ao lugar e ao tempo. Uma desvantagem é o uso excessivo da linguagem escrita, em detrimento de outras formas de contato.

A comunicação síncrona requer a participação simultânea de todos os envolvidos (alunos e professores), tendo a vantagem de ser uma interação "em tempo real". Esta interação pode ser realizada através de TV interativa, teleconferência, videoconferência e/ou chat. 
A utilização de tecnologias em processos educacionais tem vários objetivos, desde abrilhantar uma aula e motivar os alunos, até atingir um grande contingente populacional. Para cumprir esta tarefa, é necessário o uso das TICs (UDESC, 2001). Os educadores devem permanecer focalizados nos resultados de aprendizagem e não na tecnologia de distribuição, por mais que a tecnologia desempenhe um papel chave na distribuição de EAD.

É importante que as informações e os materiais sejam usados de modo intencional, não aleatório e tecnologicamente orientado nas atividades de ensinoaprendizagem, pois não possuem um valor de per si. Sua possível relevância e significação existe em função: 1) dos propósitos (intencionalidade); 2) das concepções norteadoras das ações da importância que possam exercer para a aprendizagem, pois intermediam os sujeitos (professor-alunoscomunidade) e 3) do conhecimento (Fiorentini, 2002).

Nesse panorama, as TICs introduziram enormes possibilidades de interação, intercâmbio de idéias e materiais, entre alunos e professores, nos alunos entre si e nos professores entre si. De acordo com Fiorentini (2002), isto configura as comunidades de aprendizagem em rede, bidirecionais e cooperativas.

Usando uma abordagem integrada, a tarefa do educador e da instituição é selecionar com cuidado as opções tecnológicas disponíveis, a fim de estabelecer uma mistura de mídias educacionais que atendam às necessidades dos aprendizes de maneira eficaz e economicamente prudente.

Conforme Moore e Kearsley (1996), um dos piores erros que uma organização ou um instrutor podem fazer é escolher uma única mídia. A escolha das mídias adequadas deve ser realizada para cada curso, para cada programa: cada um tem seus diferentes objetivos, diferentes alunos e diferentes ambientes de aprendizagem. A tabela 1 a seguir, apresenta os pontos e fracos de cada uma das mídias, segundo Moore e Kearsley (1996).

Tabela 1 - Pontos Fortes e Pontos Fracos das Diferentes Mídias

\begin{tabular}{|c|c|c|}
\hline & Pontos Fortes & Pontos Fracos \\
\hline Impresso & $\begin{array}{r}\text { Barato; Denso em informaçốes; } \\
\text { Confiável; Uso controlado pelo aluno }\end{array}$ & Passivo \\
\hline $\begin{array}{l}\text { Áudio/ } \\
\text { Vídeo }\end{array}$ & $\begin{array}{r}\text { Dinâmico; Denso em informaçôes; Uso } \\
\text { controlado pelo aluno; Experiência } \\
\text { "viva" em termos visuais }\end{array}$ & Tempo de desenvolvimento/Custo \\
\hline $\begin{array}{r}\text { Rádio/ } \\
\text { Televisấo }\end{array}$ & Dinâmico; Distribuição em massa & $\begin{array}{r}\text { Tempo de desenvolvimento/Custo; } \\
\text { Uso em real-time }\end{array}$ \\
\hline $\begin{array}{r}\text { Teleconfer } \\
\text { ência }\end{array}$ & Interativo; Participativo & $\begin{array}{r}\text { Complexidade; Năo confiável; Uso em } \\
\text { real-time }\end{array}$ \\
\hline $\begin{array}{r}\text { Computa- } \\
\text { dores }\end{array}$ & Multimídia;; Dinâmico & $\begin{array}{r}\text { Necessidade do equipamento; Tempo de } \\
\text { desenvolvimento/Custo }\end{array}$ \\
\hline
\end{tabular}

Fonte: baseado em Moore e Kearsley (1996)

Se por um lado, a EAD promove um conceito de autonomia por parte do aluno, por outro lado aparece uma necessidade de interação e de contato aluno/aluno e de aluno/professor, resultando como requisito uma demanda por novas maneiras pelas quais os alunos possam estar conectados (interagindo) para receber apoio e realimentação, o que resulta essencial para se manterem motivados (Tarouco, 2002).

De acordo com Litwin (1997), a Tecnologia Educacional, assim como a Didática, preocupase com as práticas do ensino, mas vai mais além, pois inclui entre suas preocupações o exame da teoria da comunicação e dos novos desenvolvimentos tecnológicos: a informática, o vídeo, a TV, o rádio, o áudio e os impressos. 
Sabe-se hoje que a tecnologia sozinha não é capaz de concretizar tal transformação. Os responsáveis pela estruturação dos cursos, pelo desenvolvimento do projeto pedagógico é que, após a primeira etapa de detalhamento do curso, devem determinar qual tecnologia será a mais apropriada para dar suporte à toda estrutura do curso.

\section{Objetivos da Investigação e Metodologia da Investigação}

Além do levantamento bibliográfico para a construção do referencial teórico (Malhotra, 1999), a metodologia utilizada neste trabalho foi o estudo de caso, devido às questões básicas de pesquisa, ausência de controle dos eventos comportamentais e ênfase nos eventos contemporâneos (Yin, 2001).

A aplicação da metodologia de estudo de caso foi realizada por meio de uma série de entrevistas com os coordenadores do Centro de Educação a Distância em questão, utilizando um protocolo elaborado especificamente para este fim. O caso em

estudo é de um curso do Gvnet - Programa de Educação a Distância da FGV-EAESP, Escola de Administração de Empresas de São Paulo da Fundação Getulio Vargas.

Dando continuidade aos programas voltados à formação profissional, esse Programa desenvolveu o GVnext - Curso de Especialização em Negócios para Executivos.

O objetivo deste paper é analisar os processos educacionais permeados pela tecnologia de informação que são utilizados pelo GVnet no curso a distância GVnext. A questão básica desta pesquisa: como são usadas as TICs nos processos educacionais no curso a distância no GVnext - Curso de Especialização em Negócios para Executivos?

\section{Análise do Caso}

Descrição do Curso

O Curso de Especialização em Negócios para Executivos - GVnext, é uma pósgraduação lato sensu, com 502 horas-aula de atividades, a ser cursado ao longo de 18 meses ou três semestres letivos. O curso utiliza uma combinação de tecnologias e metodologias avançadas de ensino e aprendizado a distância, combinadas com algumas metodologias tradicionais do ensino presencial, preservando-se a essência do relacionamento pessoal, através dos seminários presenciais.

Objetivos Gerais do curso GVnext

O GVnext está sintonizado às capacitações que um executivo deve adquirir para beneficiarse das transformações que se observam no atual ambiente de negócios:

- a metodologia estimula o desenvolvimento da autonomia na solução de problemas, apacitando o participante a criar seus próprios caminhos;

- há um fortalecimento da habilidade de atuação em equipe, privilegiando a agregação de competências interdisciplinares. Como resultado, os participantes se habilitam a elaborar análises mais profundas e abrangentes, compreendendo melhor os diversos fatores que influenciam o ambiente de negócios;

- promove-se a capacidade de atuação em equipes virtuais, com trabalho cooperativo remoto.

O principal objetivo do GVnext é de estimular o profissional a alcançar e identificar os requisitos críticos para o sucesso profissional nos dias hoje, ao mesmo tempo que amplia e fortalece suas redes de relacionamentos.

Concepção do Programa

O conteúdo e atividades de ensino-aprendizagem de cada disciplina visam a aplicação conceitual e teórica num Plano de Negócios. O Plano de Negócios será concretizado a partir das interações e atividades propostas nos seminários presenciais.

O curso é semipresencial que utiliza-se de tecnologias educacionais e metodologias de ensino e aprendizado a distância. Ao mesmo tempo em que se beneficia da flexibilidade e 
das facilidades da tecnologia, preserva os contatos pessoais entre alunos e professores. Isso fortalece o grupo e estimula o processo de aprendizagem por meio da troca de experiências. Os alunos que se encontram na sede da IES podem assistir às aulas nas instalações da instituição e os alunos que por questões geográficas se encontrem em outras cidades, estados e países, assistirão às aulas via Webcast (aulas ao vivo em formato de streaming de vídeo transmitidas via Internet). Os alunos participam das aulas através do seu computador, em casa, no trabalho ou de qualquer outro lugar desde que esteja conectado a um computador.

- O curso apresenta no seu modelo conceptual duas sessões plenárias (obrigatórias), no início e no final do programa, que representam uma oportunidade em termos de integração de todos os participantes e possibilita a construção de redes de relacionamentos, um dos principais patrimônios do executivo atual.

Além das sessões plenárias, o aluno deverá participar de três seminários presenciais que sãooferecidos em períodos pré-estabelecidos (após a conclusão de um conjunto de disciplinas-chave). Os seminários temáticos presenciais têm por objetivo fazer a consolidação dos conhecimentos teóricos e práticos adquiridos ao longo do processo de ensino-aprendizagem das disciplinas e desenvolver atividades de aplicabilidade e contribuição para o desenvolvimento das habilidades e capacidades dos alunos. Assim, os alunos adquirem progressivo domínio das principais aptidões, tendências e recursos que estão modificando os métodos de atuação profissional nas organizações em geral e especificamente em suas organizações, preparando-se para melhor absorverem e capitalizarem as transformações da sociedade do conhecimento.

Formato e Detalhes das Atividades de Aprendizagem

As estratégias de aprendizagem são veículos ou meios que são desenvolvidos para transmitir fatos, idéias, conceitos, habilidades e atitudes para o processo de cognição e ação do aluno. A aprendizagem se dá através das atividades e materiais desenvolvidos pela Coordenação Acadêmico-pedagógica juntamente com os professores das disciplinas. As atividades e materiais são desenvolvidos com base na análise do público alvo, metodologia de ensino-aprendizagem, a qual mescla estratégias dirigidas (ou centradas) no professor como aula expositiva, preleção, questionamentos, demonstrações e atividades dirigidas (ou centradas) nos alunos, como trabalho colaborativo em grupo e aprendizagem pela descoberta.

$>$ Videoconferência / Webcast

Muito similar à sessão presencial, uma videoconferência/webcast é como uma aula tradicional, ministrada a distância, em tempo real. O diferencial é a interação, pois os professores além de apresentarem os conceitos, interagirão com os alunos que estão presentes e os alunos a distância. Os alunos são estimulados a interagir com o professor por meio de perguntas, observações, depoimentos etc, como se estivessem numa mesma sala de aula;

Conteúdo de Auto-aprendizagem / LO

Auto-desenvolvimento via Internet: nesta atividade assíncrona , o aluno segue, via Internet, um roteiro de aprendizado dirigido, no qual pode se aprofundar no conteúdo da disciplina com leituras, visitas a sites selecionados etc. $\mathrm{O}$ aluno escolhe livremente os horários e locais de sua conveniência: basta acessar a Internet, em qualquer lugar ou momento, para iniciar a sessão de auto-desenvolvimento. Deverá conter exercícios para dar embasamento teórico para as aulas de videoconferência/ webcast, chats e fóruns;

$>$ Chat

Interação on-line via Internet (chat): nesta atividade síncrona, em ambiente informal, os alunos são encorajados a participar: o professor propõe questões e reflexões a serem 
debatidas pelo grupo, estimulando os participantes a fazerem análises profundas sobre os temas selecionados. A dinâmica do chat age diretamente no desenvolvimento das três competências críticas: pensamento $360^{\circ}$, autonomia e atuação em equipes virtuais. As sessões são gravadas, formando um acervo de referência, de forma que se pode, posteriormente, consultar o conteúdo e a evolução das discussões;

Fórum de Discussão

É um processo de interação assíncrona via Internet, em espaço virtual específico, voltado ao aprofundamento e exploração de temas selecionados. Espera-se, dos alunos, intensa participação, de forma que troquem entre si experiências e conhecimentos. Através de questões e temas para discussão propostos pelos professores, os alunos são estimulados a refletir sobre os diversos tópicos de cada disciplina. Esta atividade é tutorada: há um acompanhamento individualizado do desempenho, contribuições, dúvidas e questionamentos de cada aluno;

$>$ Prova de avaliação - presencial

Desenvolveu-se uma nova metodologia de provas, na qual o aluno conhece as questões com antecedência e se prepara para respondê-las individualmente, sem consulta, em dia e horário marcados. As questões são sempre voltadas à aplicação dos conhecimentos vistos na disciplina, estimulando o aluno a entender como os conceitos se encaixam no mundo real e, particularmente, no seu próprio dia-a-dia. O preparo para a prova exige que o aluno vá a campo e converse com especialistas da empresa em que atua, alavancando sua compreensão sobre a realidade de negócios. Isto desenvolve sua autonomia e o Pensamento $360^{\circ}$;

$>$ Trabalhos individuais e em grupo

Os trabalhos poderão ser realizados pelos alunos sob supervisão e orientação pedagógica. $O$ professor propõe questões e temas a serem desenvolvidos, sempre focando aspectos da realidade, a fim de ampliar a exploração de conceitos e contextualizar sua aplicabilidade ao ambiente de negócios;

$>$ Jogo de simulação de negócios

Será realizado via Internet. No último semestre os alunos aplicam, na prática, os conhecimentos adquiridos nas diversas disciplinas, através da atuação em equipes no Simulação de Negócios. É um ambiente lúdico que proporciona um contexto dinâmico e desafiador e leva à melhoria da capacidade analítico-decisória. A própria concepção do jogo faz com que sejam estimuladas as três competências críticas: autonomia, pensamento $360^{\circ} \mathrm{e}$ atuação em equipes virtuais;

$>$ Monografia, ao final do curso

Esta última etapa é uma oportunidade para que cada aluno estude um assunto ligado à vida de sua organização e dê sua contribuição quanto a possíveis sugestões de melhoria. Isto enriquece não só o processo de aprendizagem de cada participante, como também acaba por ser uma rica fonte de propostas concretas para ganhos incrementais no processo de gestão da organização.

Metodologia de Ensino

O curso está baseado em uma metodologia híbrida de aprendizagem que é chamada educação distribuída. Ela é uma combinação de educação a distância e educação tradicional, de forma a aproveitar as facilidades e flexibilidade das tecnologias de ensino a distância, mantendo os contatos pessoais que fortalecem o grupo e estimulam o processo de aprendizagem através da troca de experiências.

A metodologia baseia-se na teoria cognitivista, na qual o processo mental de aquisição de informação, durante a aprendizagem, recebe o enfoque principal. O aluno é estimulado a adquirir conhecimento e habilidades através de atividades que são prédeterminadas, com objetivos e propósitos específicos. Além disso, outras características cognitivas são levadas 
em consideração, tais como o aprendizado prévio, o nível de preparação e capacidade do aluno (que é analisado no processo seletivo), compreensão de leitura; e, na parte afetiva, as características são a motivação, sua visão pessoal, relacionamento pessoal e relacionamento com o conteúdo.

A teoria construtivista é também de grande importância no desenvolvimento da metodologia do curso. O seu paradigma diz que a aprendizagem é construída. Sendo assim, o modelo incentiva a interação social durante o processo de aprendizagem, pois os alunos são estimulados para interagir uns com os outros, criando assim um ambiente de troca de informação e colaboração. $\mathrm{O}$ curso GVnext está focado no aprendizado centrado no aluno, sendo que a troca de experiências entre os participantes desempenha um papel central na construção do conhecimento.

Se por um lado as tecnologias trazem grande flexibilidade ao quebrar as barreiras do tempo (atividades assíncronas) e do espaço (atividades a distância), os contatos pessoais entre alunos e professores fortalecem o grupo e estimulam o processo de aprendizagem através da troca de experiências.

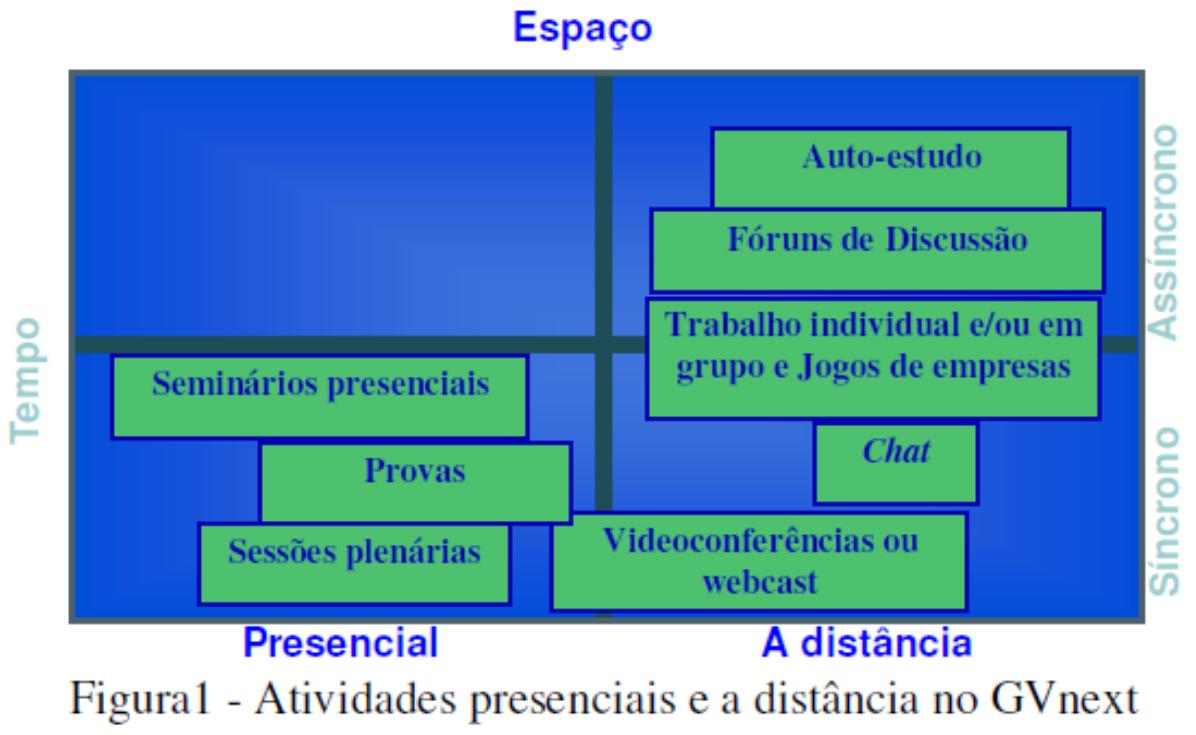

A carga horária do curso é formada da seguinte forma: 10 disciplinas obrigatórias, cada uma compreende 32 horas-aula, dispostas em cinco módulos semanais, conforme figura 2 , abaixo; 2 disciplinas de nivelamento, cada uma compreende 18 horas-aula de conteúdo online, disposta em 4 módulos semanais; 3 disciplinas eletivas on-line e cada uma compreende 20 horas-aula de conteúdo online;

Jogo de Simulação de Negócios, que é um Jogo de Empresas via Internet, e 3 seminários temáticos presenciais. 


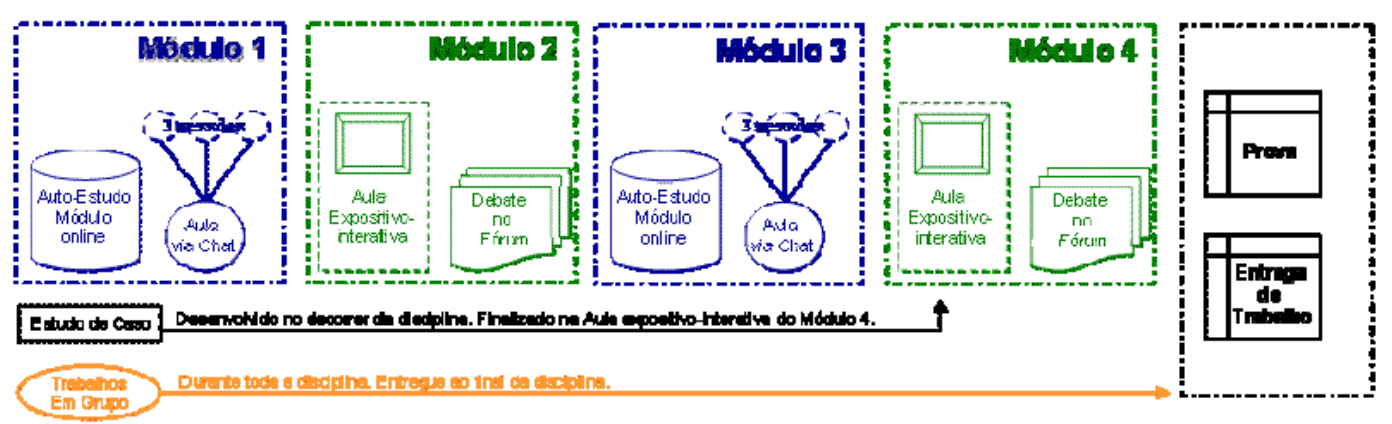

Figura 2 - Estrutura das Disciplinas

Estratégia de Aprendizado

As estratégias de aprendizado são as atividades e materiais desenvolvidos pela Coordenação Acadêmico-pedagógica juntamente com os professores das disciplinas.

Todo o material é desenvolvido seguindo estratégias cognitivas como o "chunking", princípio que aplica medidas efetivas para a comunicação da informação às pessoas. Assim, os textos são estruturados e divididos em pequenas unidades, parágrafos e marcadores. Além do uso de mnemônicos, analogias, e imagens para o estímulo visual.

O ambiente de colaboração entre alunos e professores é baseado em estratégias construtivistas, as quais incentivam o debate, colaboração, discussão, interpretação, reflexão e construção do conhecimento, habilidades e atitudes.

\section{Interdisciplinaridade}

As disciplinas que compõem o curso são ministradas numa abordagem multidisciplinar, fazendo com que o aluno perceba as inter-relações das diversas áreas funcionais de uma organização. Adicionalmente, o Jogo de Empresas é, por sua própria essência, uma abordagem interdisciplinar na gestão de negócios.

Sistemas de Avaliação

Este curso tem controle de notas e presença nas atividades, sejam elas presenciais ou a distância. Em cada disciplina, como requisitos mínimos, o aluno deve ter presença de pelo menos $80 \%$ e nota mínima igual ou superior a 6 numa escala de 0 a 10 .

Adicionalmente, sua média global final deve ser igual ou superior a 7,0.

\section{Conclusão}

O sucesso de um curso a distância depende muito da escolha de uma linguagem pedagógica apropriada à aprendizagem, suportada pelas diversas mídias disponíveis, estruturando processos, definindo objetivos e problemas educacionais utilizando, para tanto, as técnicas de desenho instrucional. Nenhuma tecnologia pode resolver todos os tipos de problemas, e o aprendizado depende mais da forma como esta tecnologia está aplicada no curso, do que do tipo de tecnologia utilizada.

As metodologias de ensino e as TICs adotadas pelo GVnext apresentam diversos aspectos de flexibilidade: exceto para as atividades presenciais, o curso pode ser acompanhado em casa ou em qualquer outro lugar escolhido pelo aluno; os materiais que compõem o curso são desenvolvidos por diferentes professores, não somente pelo instrutor responsável pelo curso; o professor (tutor) que é responsável por um estudante não é necessariamente parte da equipe que desenvolveu o material do curso; os cursos são disponibilizados em diversas cidades. Neste caso, pôde-se concluir que as tecnologias de informação e comunicação possibilitaram uma maior facilidade de acessos e posicionamentos entre alunos e professores. 
No futuro, os benefícios da implantação das TICs nos processos educacionais também serão sentidos no ensino presencial. A mudança na educação tradicional está sendo implantada aos poucos, de forma gradativa, através da aplicação das TICs na educação. Neste sentido, a EAD tem contribuído muito para esta reestruturação, pois tem exigido uma postura diferente dos professores, dos alunos e na metodologia de ensino.

Mas, o que é imperativo nos dias de hoje não é somente aprender, mas sim "aprender a aprender". Para tanto, é necessário que a relação pedagógica seja elaborada com base metodológica e planejamento para cada curso. Ao professor caberá o maior esforço reconstrutivo neste processo, pois será necessário agrupar todas as teorias modernas de aprendizagem para que os objetivos dos cursos sejam alcançados.

Possivelmente, a principal característica do GVnext é que ele partiu de uma concepção inteiramente nova: sua criação foi norteada pela identificação das possibilidades viabilizadas pelas tecnologia, mas que não seriam exeqüíveis no ambiente convencional.

O curso analisado no decorrer deste estudo pode ser classificado como um ambiente de Aprendizagem Colaborativa porque estimula a criação de ambientes de comunidades. A base do curso é formada de atividades colaborativas, pesquisa intensiva e projetos em pequenos grupos. Este se caracteriza por ser um ambiente muito integrado, que incentiva fortemente a comunicação síncrona a distância entre os alunos, buscando a criação de uma comunidade de aprendizagem. Observa-se que neste curso a preocupação da IES com o aprendizado de forma colaborativa, através de atividades em grupos e pesquisa intensiva.

Resumidamente, podemos concluir que as metodologias de ensino e a plataforma adotadas pelo GVnext apresentam diversos aspectos de flexibilidade: exceto para as atividades presenciais, o curso pode ser acompanhado em casa ou em qualquer outro lugar escolhido pelo aluno; os materiais que compõem o curso são desenvolvidos por diferentes professores, não somente pelo instrutor responsável pelo curso; o professor que é responsável por um estudante não é necessariamente parte da equipe que desenvolveu o material do curso; os cursos são disponibilizados em diversas cidades.

A taxa de evasão varia de acordo com a localização do aluno e também de acordo com a turma, e situa-se entre 5 e $10 \%$. Sabemos, porém que a falta de suporte técnico e dificuldades de acesso ao ambiente, também como a facilidade de sua navegação são fatores que contribuem para elevar a taxa de evasão de alunos a distância.

Neste caso, nota-se claramente que as tecnologias de informação e comunicação adotada pelo GVnext possibilitaram uma maior facilidade de acessos e posicionamentos entre alunos e professores, elevando não só o nível de satisfação dos alunos em relação à plataforma Blackboard, mas também como a diminuição do índice de evasão dos alunos. Cabe destacar que o suporte técnico oferecido no decorrer do curso é de vital importância no processo de aprendizagem dos alunos.

Uma vez que aprender se tornará uma atividade a ser prolongada por toda a vida, é preciso buscar desenvolver um ambiente que permita o compartilhamento de experiências entre os envolvidos neste processo, a fim de criar comunidades de aprendizagem. $O$ comprometimento de alunos e professores envolvidos será decisivo neste processo de ensino.

Referências Bibliográficas

FIORENTINI, L. M. R. Materiais didáticos escritos nos processos formativos a distância. In: CONGRESSO DE ENSINO SUPERIOR A DISTÂNCIA, I, 2002.

Petrópolis. Anais. Petrópolis: EsuD, 2002.

JENSEN, C.; FARNHAM, S. D., DRUCKER, S. M. e KOLLOCK, P. The Effect of Communication Modality on Cooperation in Online Environments. (1999).

Redmond: Microsoft Research. (MSR-TR-99-75). 
LITWIN, E. Tecnologia Educacional: política, história e propostas. Porto Alegre: Artes Médicas, 1997.

MAIER, P. e WARREN A. Integr@ting Technology in Learning and Teaching. London: Kogan Page, 2000.

MALHOTRA, N. K. Marketing Research: An Applied Orientation. Upper Saddle River: Prentice Hall, 2001. $3^{\text {a }}$ edição.

MOORE, M. \& KEARSLEY, G. Distance Education - A Systems View. Belmont: Wadsworth, 1996.

TAROUCO, L. Tecnologia para aprender/comunicar a distância. In: CONGRESSO DE ENSINO SUPERIOR A DISTÂNCIA, I, 2002. Petrópolis. Anais. Petrópolis: EsuD, 2002. UDESC - UNIVERSIDADE DO ESTADO DE SANTA CATARINA. Metodologia da

Educação a Distância. Florianópolis: Universidade do Estado de Santa Catarina, 2001.

UNIVERSIDADE DE OHIO. Distance Education at a Glance. Disponível em: $<$ http://www.cead.puc-rio.br/tutorial/>. Acesso em: 23 ago. 2002.

UNIVERSITY OF MARYLAND UNIVERSITY COLLEGE - Institute for Distance Education - Disponível em: <http://www.umuc.edu/ide/modldata.html\#desc-a $>$.

Acesso em: 18 nov. 2001.

VYGOTSKY, L. S. A formação social da mente: o desenvolvimento dos processos psicológicos superiores. São Paulo: Martins Fontes, 1998.

YIN, R. Estudo de caso: Planejamento e Métodos. Porto Alegre: Bookman, 2001. $2^{\text {a }}$ edição. 